S H O R T C O M U N I C A T I O N

\title{
Response of workers of Atta sexdens rubropilosa (Hymenoptera: Formicidae) to mandibular gland compounds of virgin males and females
}

\author{
J. MAURÍCIO S. B E N T O ${ }^{1}$, T E R E Z I N H A . C. D E L L A L U C I A ${ }^{2}$, \\ R U T H R. D O NA S C I M E T O ${ }^{3}$, JA N B E R M A N N ${ }^{4}$ and \\ E. D AVID MOR G A N ${ }^{5}$ \\ ${ }^{1}$ Depto de Entomologia, Fitopatologia e Zool. Agrícola, Universidade de São Paulo, Piracicaba-SP, Brazil, ${ }^{2}$ Depto de Biologia \\ Animal, Universidade Federal de Viçosa, Viçosa-MG, Brazil, ${ }^{3}$ Institute of Chemistry and Biotechnology, Universidade Federal \\ de Alagoas, Maceió-AL, Brazil, ${ }^{4}$ Instituto de Química, Pontificia Universidad Católica de Valparaíso, Valparaíso, Chile and \\ ${ }^{5}$ Chemical Ecology Group, Lennard-Jones Laboratory, Keele University, Staffordshire, U.K.
}

\begin{abstract}
The secretion from the mandibular glands of males of the leaf-cutting ant Atta sexdens rubropilosa is responsible for the reaction of workers outside the nest at the time of sexual swarming. Workers respond with excitability and aggression when presented with the natural mixture of 4-methyl-3-heptanol and 4-methyl-3-heptanone, which is contained in the secretion of the male mandibular glands. Workers respond quickly to fractional amounts of one male equivalent. 4-Methyl-3-heptanone, from the virgin female mandibular glands causes much less response in workers, whereas an equimolar mixture of male and female pheromones gives a still less clear response. The male pheromone plays the most important part in the communication of workers outside the nest at this time.
\end{abstract}

Key words. Aggression, excitation, leaf-cutting ants, 4-methyl-3-heptanol, 4-methyl3-heptanone, pheromone, virgin males, virgin females, worker behaviour.

\section{Introduction}

Immediately before the nuptial flights of leaf-cutting ants, it is common to observe great excitement and aggressiveness in the workers on the surface near the nests, in contrast to other times of the year. This behaviour is observed in several leaf-cutting ant species (Autuori, 1941; Moser, 1967; Mariconi, 1970; Moser et al., 2004). It is suggested that the behaviour is a response to male mandibular gland secretions, and leads to protection of the sexual forms (virgin males and females) during swarming (Fowler, 1982). It is also claimed that the response helps workers to deter recently mated queens that might try to establish new nests too close to the established colony (Fowler, 1982; Vander Meer \& Alonso, 1998).

The first study of mandibular glands of Atta sexdens rubropilosa worker identified citral (the equilibrium mixture of geranial and neral) and described it as a warning or frightening

\footnotetext{
Correspondence: E. D. Morgan, Chemical Ecology Group, Lennard-Jones Laboratory, Kele University, Staffordshire ST55BG, U.K. Tel.: +44 1782 680712; fax: +44 1782 712378; e-mail: e.d.morgan@chem.keele.ac.uk
}

mixture (Butenandt et al., 1959). Later studies showed that smaller workers produce 4-methyl-3-heptanone, whereas large workers and soldiers produce a mixture dominated by citral (do Nascimento et al., 1993). The mandibular glands of virgin and mated queens essentially contain only 4-methyl-3heptanone $(5 \mu \mathrm{g}$ per individual in virgin queens, $9 \mu \mathrm{g}$ in mated queens). Unmated males produce a mixture of 4-methyl-3heptanone and 4-methyl-3-heptanol in approximately equal proportions (11 $\mu \mathrm{g}$ per individual) (do Nascimento et al., 1993). Mated males cease to contain the secretion (do Nascimento et al., 1993).

4-Methyl-3-heptanone has been identified in the mandibular glands of several other species of Atta, namely Atta bisphaerica, Atta capiguara, Atta cephalotes, Atta laevigata, Atta robusta and Atta texana (Blum et al., 1968; Riley et al., 1974; Hernández et al., 1999; Hughes et al., 2001a; Hernández et al., 2002). This compound also causes attraction in the grass-cutting ants A. bisphaerica and A. capiguara (Hughes et al., 2001b).

Subsequently, the chirality of 4-methyl-3-heptanone and 4-methyl-3-heptanol from virgin males and females was determined, and $(S)-(+)$-4-methyl-3-heptanone essentially comprises the only material in the mandibular glands of 
Table 1. Intensity of reaction of workers of Atta sexdens rubropilosa to synthetic male mandibular pheromone (equal quantities of racemic 4-methyl-3heptanone and racemic 4-methyl-3-heptanol, containing the stated amounts of the active chiral forms).

\begin{tabular}{lcll}
\hline & & Response intensity $(\%)$ \\
\cline { 3 - 4 } Male equivalents & Workers responding, mean \pm SD $(\%)$ & Type 2 & $32.5^{\mathrm{a}}$ \\
\hline 0.025 & $52.5 \pm 10.8^{\mathrm{b}}$ & $25^{\mathrm{a}}$ & $20^{\mathrm{d}}$ \\
0.05 & $60 \pm 5.8^{\mathrm{b}}$ & $27.5^{\mathrm{a}}$ & $35^{\mathrm{c}}$ \\
0.10 & $62.5 \pm 2.5^{\mathrm{b}}$ & $25^{\mathrm{a}}$ & $57.5^{\mathrm{b}}$ \\
0.25 & $82.5 \pm 4.3^{\mathrm{a}}$ & $20^{\mathrm{a}}$ & $73.7^{\mathrm{a}}$ \\
0.50 & $93.7 \pm 9.5^{\mathrm{a}}$ & $5^{\mathrm{b}}$ & $0^{\mathrm{e}}$ \\
Control & $5 \pm 5.8^{\mathrm{c}}$ & & Type 1 \\
\hline
\end{tabular}

Response intensity: type 1, workers turning towards source and opening and closing mandibles; type 2, same as type 1 with workers running excitedly over the test area. Means followed by the same superscript letter within a column do not differ among themselves by Tukey's test $(P=0.05)$.

mated and unmated queens. In males, it is a mixture of $(3 S, 4 S)$-4-methyl-3-heptanol and $(3 R, 4 S)$-4-methyl-3-heptanol, together with $(S)-(+)-4-m e t h y l-3$-heptanone (do Nascimento et al., 1997).

Moser et al. (1968) in A. texana, and Riley et al. (1974) in A. cephalotes, showed that $(S)-(+)-4$-methyl-3-heptanone is the only pheromonally active compound in these species and that it is unaffected by the presence of inactive $(R)-(-)-4-$ methyl-3-heptanone. Other compounds identified in mandibular glands are inactive in behavioural assays. Little attention has been given to pheromones in sexuals, other than with respect to sexual attraction or copulation. The present study were therefore conducted with the more readily available racemic forms of 4-methyl-3-heptanone and 4-methyl-3heptanol to observe the effects of male and female mandibular pheromones on workers of $A$. sexdens rubropilosa.

\section{Materials and methods}

Tests were carried out on two nests of $A$. sexdens rubropilosa that were approximately 3 years old, and contained 4-6 L of fungus. They were kept on a wooden foraging area $(100 \times 50$ $\mathrm{cm})$ at $25 \pm 2{ }^{\circ} \mathrm{C}$ and $75 \pm 5 \% \mathrm{RH}$ under an LD $12: 12 \mathrm{~h}$ photoperiod. Bioassays were conducted in a small arena $(12 \times$ $12 \mathrm{~cm}$ with a wall $6 \mathrm{~cm}$ high around it), which was placed randomly on the feeding table to isolate ten workers of different sizes for approximately $15 \mathrm{~min}$ before the beginning of each test. For the test, a solution containing the compound or mixture to be tested was placed on a piece of filter paper ( $2 \mathrm{~cm}$ in diameter) with a microsyringe, the solvent was allowed to evaporate, and the piece of filter paper placed in the centre of the arena. For a control, a piece of filter paper treated only with the solvent was used. The number of workers that responded to the stimulus, as well as the intensity of the response was quantified, according to the modified method of Fowler (1982). The percentage response of workers was obtained from the number of workers that gave a clear alarm or aggressive reaction to the stimulus. The response was characterized by two types: in a type 1 response, the workers opened and closed their mandibles in the direction of, or on top of, the stimulus. In a type 2 response, the workers additionally performed sharp body movements and ran excitably and aggressively in a direction away from the stimulus, over the test area. Each test was independently observed and scored by two individuals. To diminish the habituation effect, four replicate experiments were performed for each concentration, at intervals of at least $4 \mathrm{~h}$, during 3 consecutive days. After this period, there was an interval of 3-5 days before the tests were repeated. Both nests were tested in the same way and the results were combined. The experiments were conducted in a completely randomized design. To determine the possible response of workers to different

Table 2. Intensity of reaction of workers of Atta sexdens rubropilosa to synthetic virgin female mandibular pheromone (racemic 4-methyl-3-heptanone containing the stated amounts of the active chiral form).

\begin{tabular}{lcll}
\hline & & Response intensity $(\%)$ \\
\cline { 3 - 4 } Female equivalents & Workers responding, mean \pm SD $(\%)$ & Type 2 & $25^{\mathrm{a}, \mathrm{b}}$ \\
\hline 0.025 & $40 \pm 10^{\mathrm{b}}$ & $40^{\mathrm{a}}$ & $32.5^{\mathrm{a}}$ \\
0.05 & $65 \pm 12.9^{\mathrm{a}}$ & $30^{\mathrm{a}}$ & $25^{\mathrm{a}, \mathrm{b}}$ \\
0.10 & $57.5 \pm 8.7^{\mathrm{a}}$ & $29^{\mathrm{a}}$ & $37.5^{\mathrm{a}}$ \\
0.25 & $67.5 \pm 11.9^{\mathrm{a}}$ & $7.5^{\mathrm{b}}$ & $32.5^{\mathrm{a}}$ \\
0.50 & $61.2 \pm 13.1^{\mathrm{a}}$ & $0^{\mathrm{b}}$ \\
Control & $7.5 \pm 0.5^{\mathrm{c}}$ & & \\
\hline
\end{tabular}

Response intensity: type 1, workers turning towards source and opening and closing mandibles; type 2 , same as type 1 with workers running excitedly over the test area. Means followed by the same superscript letter within a column do not differ among themselves by Tukey's test $(P=0.05)$. 
Table 3. Intensity of reaction of workers of Atta sexdens rubropilosa to a combination of synthetic male mandibular pheromone (equal quantities of racemic 4-methyl-3-heptanone and racemic 4-methyl-3-heptanol), and female mandibular pheromone (racemic 4-methyl-3-heptanone) all containing the stated amounts of the active chiral form.

\begin{tabular}{|c|c|c|c|c|}
\hline \multirow[b]{2}{*}{ Male equivalents } & \multirow[b]{2}{*}{ Female equivalents } & \multicolumn{3}{|l|}{ Response intensity (\%) } \\
\hline & & Workers responding, mean $\pm \mathrm{SD}(\%)$ & Type 2 & Type 1 \\
\hline 0.10 & 0.10 & $81.2 \pm 13.1^{\mathrm{a}, \mathrm{b}}$ & $27.5^{\mathrm{a}, \mathrm{b}}$ & $53.7^{\mathrm{a}, \mathrm{b}}$ \\
\hline 0.25 & 0.10 & $96.2 \pm 4.8^{\mathrm{a}}$ & $36.2^{\mathrm{a}}$ & $60^{\mathrm{a}}$ \\
\hline 0.50 & 0.10 & $67.5 \pm 5^{\mathrm{b}, \mathrm{c}}$ & $32.5^{\mathrm{a}}$ & $35^{\mathrm{a}, \mathrm{b}}$ \\
\hline 0.10 & 0.25 & $80 \pm 14.1^{\mathrm{a}, \mathrm{b}}$ & $40^{\mathrm{a}}$ & $40^{\mathrm{a}, \mathrm{b}}$ \\
\hline 0.25 & 0.25 & $70 \pm 17.3^{b}$ & $30^{\mathrm{a}, \mathrm{b}}$ & $40^{\mathrm{a}, \mathrm{b}}$ \\
\hline 0.50 & 0.25 & $66.7 \pm 11.5^{\mathrm{b}, \mathrm{c}}$ & $36^{\mathrm{a}}$ & $30.7^{b, c}$ \\
\hline 0.10 & 0.50 & $45 \pm 5.8^{d}$ & $30^{\mathrm{a}, \mathrm{b}}$ & $15^{\mathrm{b}, \mathrm{c}}$ \\
\hline 0.25 & 0.50 & $32 \pm 25.2^{\mathrm{d}, \mathrm{e}}$ & $22^{\mathrm{a}, \mathrm{b}}$ & $10^{\mathrm{b}, \mathrm{c}}$ \\
\hline 0.50 & 0.50 & $20 \pm 8.2^{\mathrm{d}, \mathrm{e}}$ & $15^{\mathrm{a}, \mathrm{b}}$ & $5^{c}$ \\
\hline Control & - & $5 \pm 5^{\mathrm{e}}$ & $5^{b}$ & $0^{\mathrm{c}}$ \\
\hline
\end{tabular}

Response intensity: type 1, workers turning towards source and opening and closing mandibles; type 2 , same as type 1 with workers running excitedly over the test area. Means followed by the same superscript letter within a column do not differ among themselves by Tukey's test $(P=0.05)$.

synthetic mandibular gland compounds of virgin males and females, the data for behaviour response and intensity (types 1 and 2) were submitted to analysis of variance, and the means were compared by Tukey's test $(P<0.05)$.

To determine the isomer composition of the synthetic 4methyl-3-heptanol, a sample was chromatographed on a fused silica column $(25 \mathrm{~m} \times 0.25 \mathrm{~mm})$ coated with Hydrodex $\beta$-6-TBDM (Macherey \& Nagel, Germany) with temperature initially at $6{ }^{\circ} \mathrm{C}$ for $3 \mathrm{~min}$, then programmed to $190{ }^{\circ} \mathrm{C}$ at 2 ${ }^{\circ} \mathrm{C} \min ^{-1}$.

The synthetic 4-methyl-3-heptanol was shown to comprise $40.5 \%(3 S, 4 S)$ and $(3 R, 4 R)$ isomers and $59.5 \%(3 S, 4 R)$ and $(3 R, 4 S)$ isomers, whereas the 4-methyl-3-heptanol of male A. s. ribropilosa mandibular glands consists of equal proportions of $(3 S, 4 S)$ and $(3 R, 4 S)$ isomers (do Nascimento et al., 1997). Therefore, in $100 \mathrm{ng}$ of synthetic mixture, there are 20 $\mathrm{ng}$ of $(3 S, 4 S)$ isomer and $30 \mathrm{ng}$ of $(3 R, 4 S)$ isomer. Although this differs from the natural ratio, we have made the approximation that $100 \mathrm{ng}$ of synthetic mixture contains $50 \mathrm{ng}$ of natural pheromone.

A solution of synthetic 4-methyl-3-heptanol (>99\%, mixture of enantiomers, Aldrich, U.K) was prepared in hexane (HPLC grade, Fisher, U.K.) to give a concentration of $10 \mu \mathrm{g}$ in $10 \mu \mathrm{L}$, which represents $500 \mathrm{ng} \mu \mathrm{L}^{-1}$ of the active mixture of $(3 S, 4 S)$-4-methyl-3-heptanol and $(3 R, 4 S)$-4-methyl-3heptanol. Racemic 4-methyl-3-heptanone was produced by chromic acid oxidation of the corresponding alcohol and determined to be $99 \%$ pure by gas chromatography. This too was prepared as a solution $(10 \mu \mathrm{g}$ in $10 \mu \mathrm{L})$ in hexane, so that it contained $500 \mathrm{ng} \mu \mathrm{L}^{-1}$ of the active form $(S)-(+)-4-$ methyl-3-heptanone. Further dilutions were made to represent fractional male and female equivalents for behavioural tests.

\section{Results and discussion}

When a stimulus corresponding to as little as $2.5 \%$ of a male mandibular gland contents was presented to a group of ten workers, half of them responded by turning towards the source and opening their mandibles (type 1 response) and $40 \%$ of those responding began to run excitedly about the arena (Table 1). Increasingly larger doses gave correspondingly stronger reactions that were significantly different when Tukey's test was applied (Table 1). At half the equivalent of the content of a male mandibular gland, $70 \%$ of the workers showed the intense response of type 2 , running about the arena with their mandibles open. Only $5 \%$ of workers showed any response to the control papers. The results obtained clearly justify the use of the racemic mixture.

When the virgin female pheromone was similarly tested, the number of workers responding was less, and the number did not increase regularly with increasing doses (Table 2). An increase was noted only with the lower dose. The variation in response of individual workers was greater, and there was less agitation and running about.

When the male and female pheromones were combined in different proportions, the greatest and most aggressive response was with the lowest proportion of female pheromone (Table 3). Variation in response of individual workers was greater, and the excitability of workers decreased as the proportion of female pheromone increased.

Workers show a clear response to the male mandibular pheromone, and a closer dose-response relationship than is evident with either the female pheromone alone or with combined male and female pheromones. This confirms the observations of Fowler (1982) that the male mandibular gland pheromone should have an important role in the aggressive and excitable response of workers at the time of swarming. Moreover, earlier experiments demonstrate that the male mandibular glands show more secretion before mating than after mating (do Nascimento et al., 1993), whereas the opposite is true for females, suggesting that female secretion is more important in some other function after mating.

That workers respond promptly to the lowest concentration of synthetic pheromone tested ( 0.025 equivalents of an average male sexual) indicates the important role of these 
volatiles in communication for the species. The progressive increase in amount of 4-methyl-3-heptanone promotes atypical behaviour, such as crawling, momentary loss of movement and repellence. We conclude that the aggressive and excitable behaviour of workers close to the nest entrances before the nuptial flight is caused largely by discharge of the equimolar mixture of 4-methyl-3-heptanone and 4-methyl-3-heptanol from the mandibular glands of the unmated males present.

\section{Acknowledgements}

We thank Conselho Nacional de Desenvolvimento Científico e Tecnológico (CNPq-RHAE), Brazil, for financial support, and Professor W. Francke for help with the chiral determination of 4-methyl-3-heptanol.

\section{References}

Autuori, M. (1941) Contribução para o conhectimento da saúva (Atta spp.). 1. Evolução do sauveio (Atta sexdens rubropilosa Forel, 1908). Arquivo do Instituto de Biologia, 12, 197-228.

Blum, M.S., Padovani, F. \& Amante, E. (1968) Alkanones and terpenes in the mandibular gland secretion of Atta species (Hymenoptera: Formicidae). Comparative Biochemistry and Physiology, 16, 291-299.

Butenandt, A., Linzen, B. \& Lindauer, M. (1959) Über einem Duftstoff aus der Mandibeldrüse der Blattschneiderameisen Atta sexdens rubropilosa Forel. Archives d'Anatomie Microscopique et de Morphologie Experimentale, 4, 13-19.

Fowler, H.G. (1982) Male induction and function of workers' excitability during swarming in leaf-cutting ants (Atta and Acromyrmex) (Hymenoptera: Formicidae). International Journal of Invertebrate Reproduction, 4, 333-335.

Hernández, J.V., Cabrera, A. \& Jaffé, K. (1999) Mandibular gland secretions in different castes of the leaf-cutter ant Atta laevigata. Journal of Chemistry Ecology, 25, 2433-2444.
Hernández, J.V., López, H. \& Jaffé, K. (2002) Nestmate recognition signals of the leaf-cutting ant Atta laevigata. Journal of Insect Physiology, 48, 287-295.

Hughes, W.O.H., Howse, P.E. \& Goulson, D. (2001b) Mandibular gland chemistry of grass-cutting ants: species, caste, and colony variation. Journal of Chemistry Ecology, 27, 109-124.

Hughes, W.O.H., Howse, P.E., Vilela, E.F. \& Goulson, D. (2001a) The response of grass-cutting ants to natural and synthetic versions of their alarm pheromone. Physiological Entomology, 26, 165-172.

Mariconi, F.A.M. (1970) As Saúvas, pp. 167. Editora Agronômica Ceres, Brazil.

Moser, J.C. (1967) Mating activities of Atta texana (Hymentoptera, Formicidae). Insectes Sociaux, 14, 95-312.

Moser, J.C., Brownlee, R.C. \& Silverstein, R.M. (1968) Alarm pheromones of the ant Atta texana. Journal of Insect Physiology, 14, $529-535$.

Moser, J.C., Reeve, J.D., Bento, J.M.S. et al. (2004) Eye size and behaviour of day- and night-flying leafcutting ant alates. Journal of Zoology, 264, 69-75.

do Nascimento, R.R., Morgan, E.D., Billen, J. et al. (1993) Variation with caste of the mandibular gland secretion in the leaf-cutting ant Atta sexdens rubropilosa. Journal of Chemical Ecology, 19, 907-918.

do Nascimento, R.R., Morgan, E.D., König, W.A. \& Della Lucia, T. M.C. (1997) Absolute configuration of 4-methyl-3-heptanone and 4-methyl-3-heptanol from mandibular glands of virgin males and females of Atta sexdens rubropilosa. Journal of Chemical Ecology, 23, 1569-1575.

Riley, R.G., Silverstein, R.M. \& Moser, J.C. (1974) Isolation, identification, synthesis and biological activity of volatile compounds from the heads of Atta ants. Journal of Insect Physiology, 20, 1629-1637.

Vander Meer, R.K. \& Alonso, L.E. (1998) Pheromone directed behavior in ants. Pheromone Communication in Social Insects (ed. by R. K. Vander Meer, M. D. Breed, M. L. Winston and K. E. Espelie), pp. 159-91. Westview Press, Boulder, Colorado.

Accepted 11 January 2007

First published online 8 May 2007 